University of Nebraska - Lincoln

DigitalCommons@University of Nebraska - Lincoln

2013

\title{
Load testing and GPR assessment for concrete bridges on military installations
}

Wilmel Varela-Ortiz

US Army Engineer Research and Development Center, Wilmel.Varela-Ortiz@usace.army.mil

Carmen Y. Lugo Cintrón

US Army Engineer Research and Development Center, Carmen.Y.Lugo@usace.army.mil

Gerardo I. Velázquez

US Army Engineer Research and Development Center, Gerardo.I.Velazquez@usace.army.mil

Terry R. Stanton

US Army Engineer Research and Development Center, Terry.R.Stanton@usace.army.mil

Follow this and additional works at: https://digitalcommons.unl.edu/usarmyresearch

Varela-Ortiz, Wilmel; Lugo Cintrón, Carmen Y.; Velázquez, Gerardo I.; and Stanton, Terry R., "Load testing and GPR assessment for concrete bridges on military installations" (2013). US Army Research. 230.

https://digitalcommons.unl.edu/usarmyresearch/230

This Article is brought to you for free and open access by the U.S. Department of Defense at DigitalCommons@University of Nebraska - Lincoln. It has been accepted for inclusion in US Army Research by an authorized administrator of DigitalCommons@University of Nebraska - Lincoln. 


\title{
Load testing and GPR assessment for concrete bridges on military installations
}

\author{
Wilmel Varela-Ortiz*, Carmen Y. Lugo Cintrón, Gerardo I. Velázquez, Terry R. Stanton \\ US Army Engineer Research and Development Center (ERDC), 3909 Halls Ferry Road, Vicksburg, MS 39180-6199, United States
}

\section{A R T I C L E I N F O}

\section{Article history:}

Received 14 July 2008

Received in revised form 2 September 2010

Accepted 28 September 2010

Available online 13 December 2010

\section{Keywords:}

Concrete bridges

Non-destructive load testing

Ground Penetrating Radar

Strain transducers

Moving loads

Safe load-carrying capacity

\begin{abstract}
A B S T R A C T
The US Army owns and maintains approximately 2000 bridges on its installations spread out in the United States and around the world. From this inventory, 67\% are concrete bridges, most of which do not have design or as-built plans to effectively evaluate their condition/capacity. In addition, military vehicles have unique characteristics that are difficult to take into account when analytical analyses are performed. For these purposes, the US Army Engineer Research and Development Center has been adapting nondestructive techniques. The most promising concept explored thus far involves bridge rating through non-destructive load testing in combination with Ground Penetrating Radar (GPR) techniques. Field load testing techniques are valuable for evaluating the capacity of existing bridges and accurately characterize the structure's live-load response while GPR techniques provide valuable information regarding the internal reinforcement as well as the condition of the concrete. This article will provide a brief description as well as the results from recent evaluations performed on reinforced concrete bridges at military installations.
\end{abstract}

(c) 2010 Published by Elsevier Ltd.

\section{Introduction}

Over the years the success of our US military forces has been dependant on the education, guidance, and training of our soldiers. In order to develop the required skills to achieve their mission the US Army has become the owner or leaser of numerous installations in the United States as well as in foreign countries. Most of the times these installations already have existing bridges, which in rare occasions have design or as-built drawings on file. Also, most of these bridges do not have a load rating analysis performed for civilian and/or military vehicles required to assure the safety of the civilian and military personnel. In addition, deficient or low load-carrying capacity bridges are among those most likely to receive costly repairs or to be replaced. For these reasons, it is important that the load-carrying capacity as well as the condition of these bridges must be determined accurately. Therefore, the Engineering Research and Development Center has been adapting nondestructive techniques to address these issues.

Ground Penetrating Radar (GPR) techniques have been adopted in order to determine the location, depth and amount of reinforcement steel within reinforced concrete structures. Then a small hole is drilled to measure the rebar size which is subsequently patched. On site member measurements combined with gathered GPR information are useful to develop "as-built" plans for the bridge superstructure. Additionally, diagnostic bridge load testing have been used to determine the safe load-carrying capacity of existing bridges comparing the actual bridge response to analytical values. Field load testing has been used for bridges on military installations since it allows the owner to reduce the conservatism of analytical rating methods and safely rate the bridge for higher loads. This article is intended to present an overview of the load testing procedure and results obtained for four different conventionally reinforced concrete bridges on military installations.

\section{Description of brides}

Four conventionally reinforced concrete bridges have been load tested in the last couple of years to determine the safe load-carrying capacity for civilian and military vehicles. These structures were chosen because all of them were classified in fair condition based on routine inspections. Each of the bridges exhibited flexural and/or temperature and shrinkage cracks on their superstructure. None of these bridges had design or as-built plans on file to calcuolate the bending moment and/or shear capacity of the superstructure. Therefore, GPR evaluations where performed for each of the bridges to develop "as-built" plans for each superstructure. Table 1 provides a brief description of the superstructure for each of the tested bridges. All of the bridges carry two lanes of traffic, one in each direction. Plan and cross section views for all the bridges will be shown in Section 3.1.

\section{Non-destructive bridge load testing}

In order to determine the safe load carrying capacities for the load tested bridges a diagnostic test was performed on each of
* Corresponding author. Tel.: +1 601634 2245; fax: +1 6016342211.

E-mail addresses: Wilmel.Varela-Ortiz@usace.army.mil (W. Varela-Ortiz), Carmen.Y.Lugo@usace.army.mil (Carmen Y. Lugo Cintrón), Gerardo.I.Velazquez@usace.army.mil (G.I. Velázquez), Terry.R.Stanton@usace.army.mil (T.R. Stanton). 
Table 1

Description of load tested concrete bridges.

\begin{tabular}{|c|c|c|c|c|c|c|}
\hline Structure's name & Superstructure type & Number of spans & Simple or continuous & Span length & Skew angle $\left(^{\circ}\right)$ & Roadway width \\
\hline FSBR 201 & Reinforced concrete beam & 1 & Simple & $8.54 \mathrm{~m}(28 \mathrm{ft})$ & 19.6 & $8.08 \mathrm{~m}(26.5 \mathrm{ft})$ \\
\hline FSBR 514 & Reinforced concrete frame & 1 & Partially fixed & $7.32 \mathrm{~m}(24 \mathrm{ft})$ & 17.0 & $8.08 \mathrm{~m}(26.5 \mathrm{ft})$ \\
\hline FSBR 1608 & Reinforced concrete slab & 3 & Continuous & $10.06 \mathrm{~m}(33 \mathrm{ft})$ & 0.0 & $8.54 \mathrm{~m}(28.0 \mathrm{ft})$ \\
\hline Bridge 2151 & Reinforced concrete beam & 5 & Simple & $8.84 \mathrm{~m}(29 \mathrm{ft})$ & 0.0 & $5.89 \mathrm{~m}(19.33 \mathrm{ft})$ \\
\hline
\end{tabular}

the structures. Diagnostic load tests were chosen instead of proof load tests because of the lower cost, shorter testing time, and less disruption to traffic [4]. Because these tests were performed on military installations it is essential to have a shorter testing time and lesser disruption to traffic to allow the military community to complete their mission. Additionally, these bridges are required to be load rated for civilian and military vehicles. While civilian vehicles are relatively easy to obtain and configure to the required load, military vehicles are not always available on the installation. Most of the times these installations are load tested because new military vehicles will be deployed. However, if the military vehicles are available, an extra effort is required to coordinate with the military community since they are required to be driven and escorted by military personnel. Furthermore, since previous routine inspection showed that these bridges were in fair condition with flexure and/or temperature and shrinkage cracks on their superstructure it

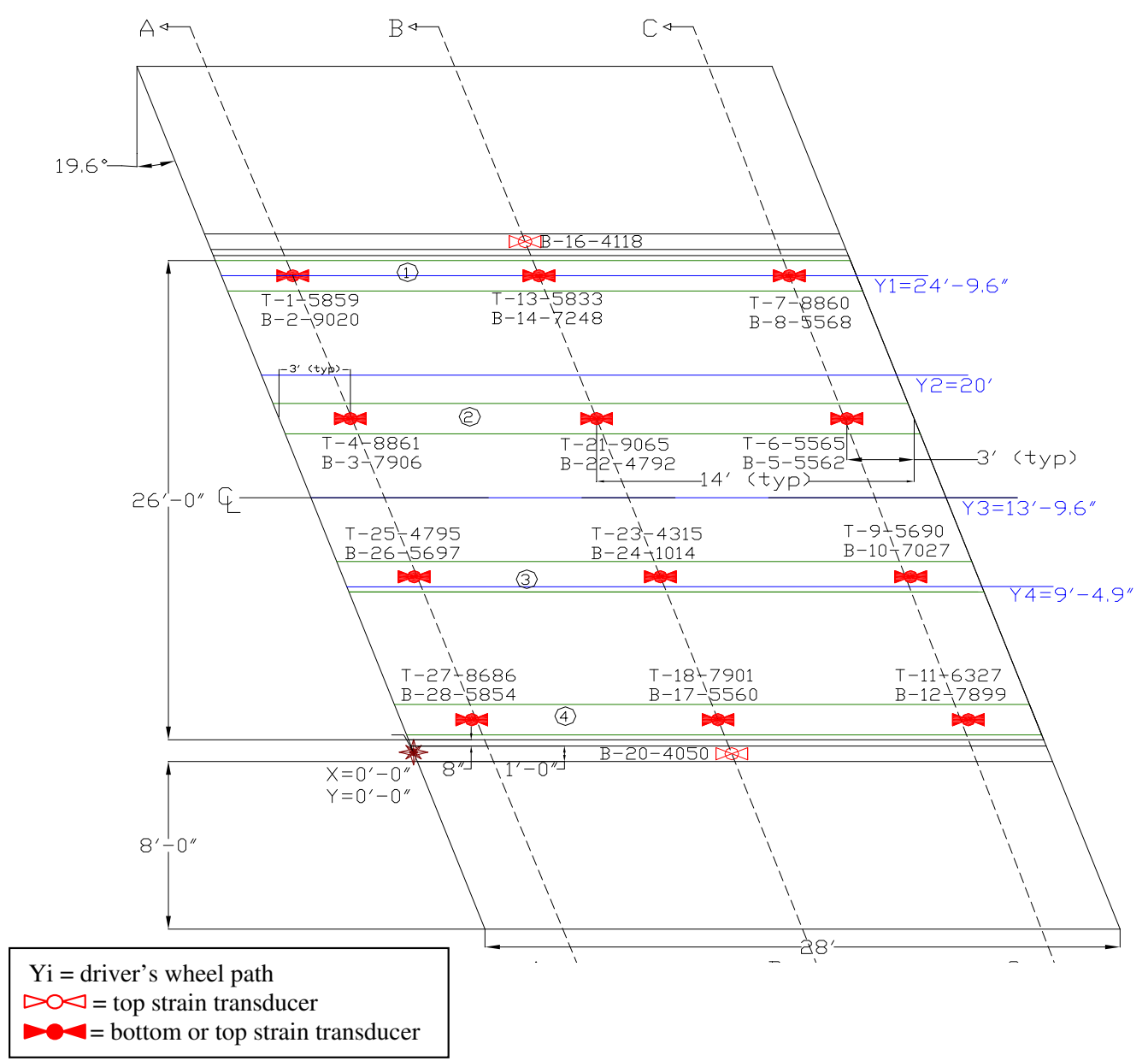

(a) Plan view

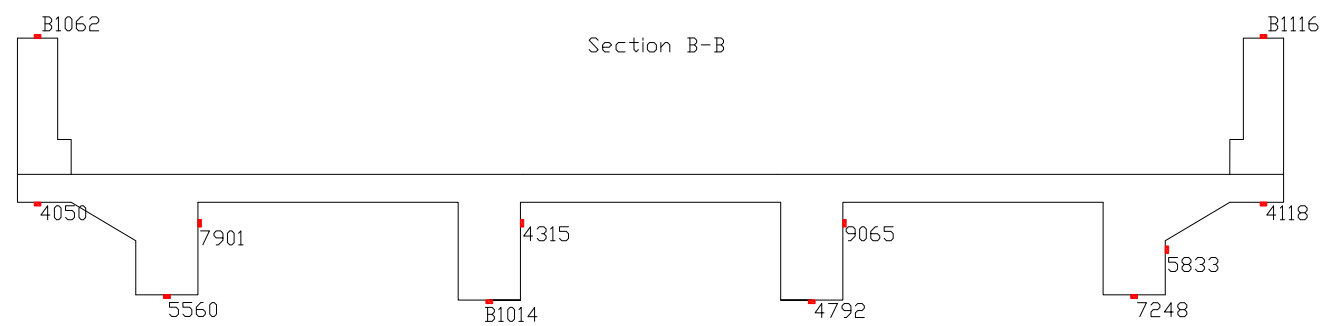

(b) Cross section

Fig. 1. Instrumentation plan for FSBR 201. 
was decided that the bridge cannot risk taking the target live load required by a proof load test.

In a load test the experimental data contains the overall resistance of the bridge where all the components work together to resist the applied load. All the different effects that can be measured in a load test include actual impact factor, actual section dimensions, unaccounted system stiffness provided by sidewalks, curbs, and railings, actual lateral and longitudinal live load distribution, bearing restrained effects, and unintended or additional composite action [3]. During these load tests the actual section dimensions, actual longitudinal and lateral load distribution factors, and unac- counted system stiffness were considered reliable to calculate a safe load-carrying capacity for each of the bridges while the other effects were not considered at all.

\subsection{Instrumentation}

The instrumentation plan for each of the superstructures is shown from Figs. 1-4. It was assumed that the middle of the span controlled the ratings and therefore it was fully instrumented in each of the bridges. Instrumentation was also located near the supports in order to capture the overall bridge behavior. To gather

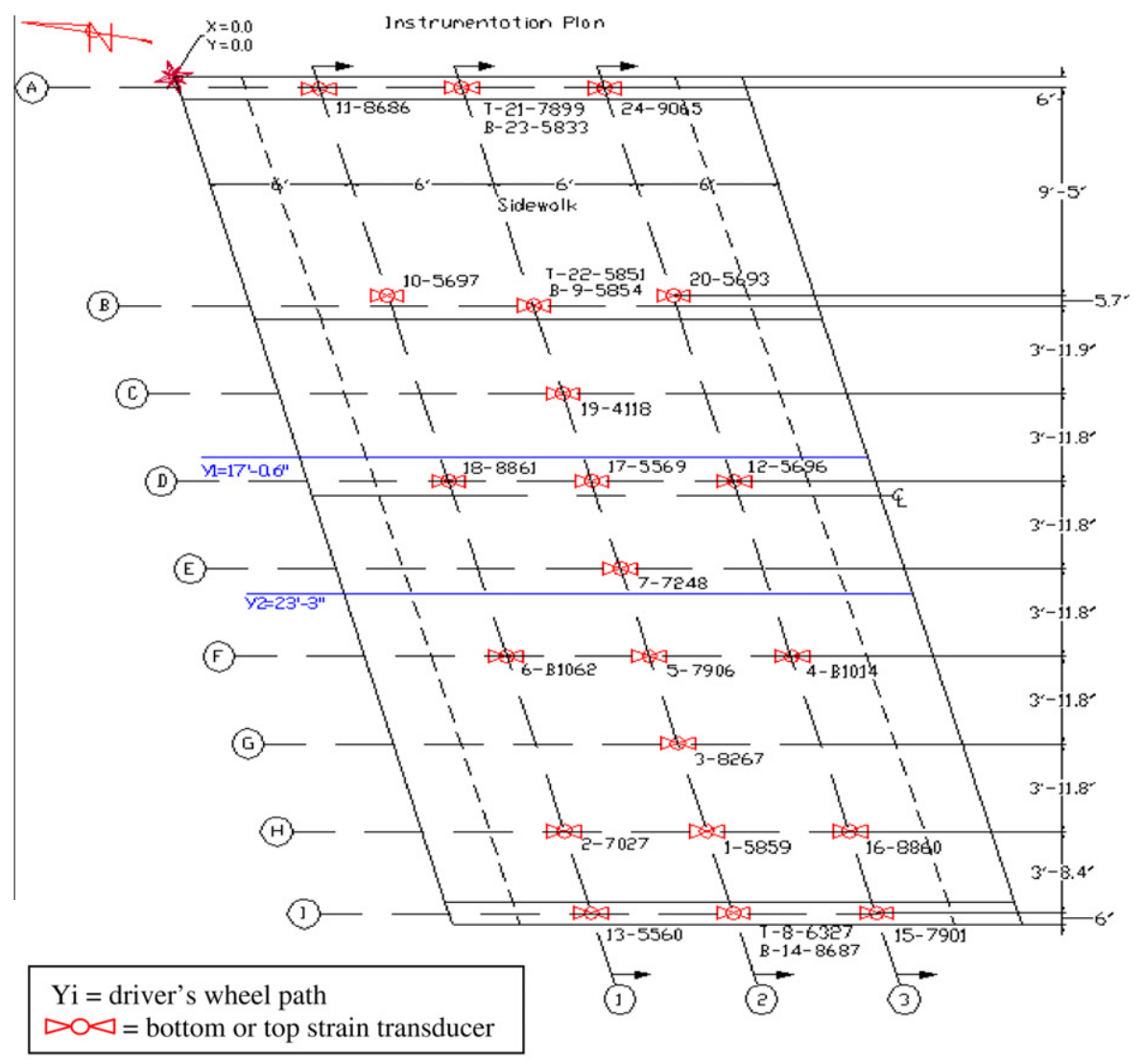

(a) Plan view

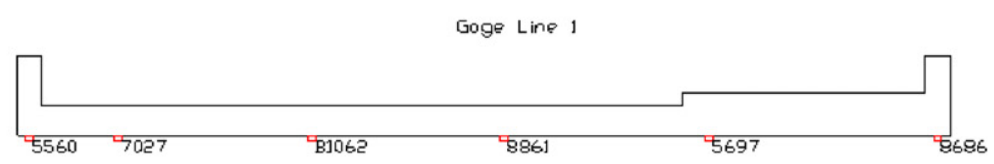

Goge Line ?

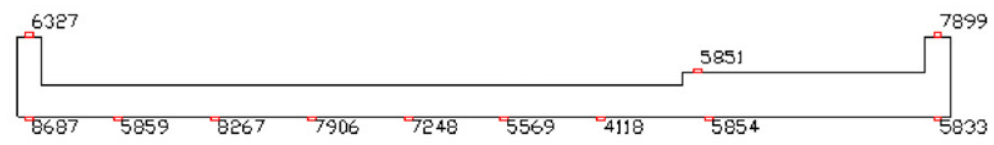

Goge Line 3

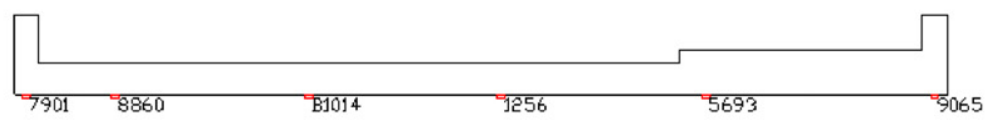

(b) Cross section

Fig. 2. Instrumentation plan for FSBR 514 


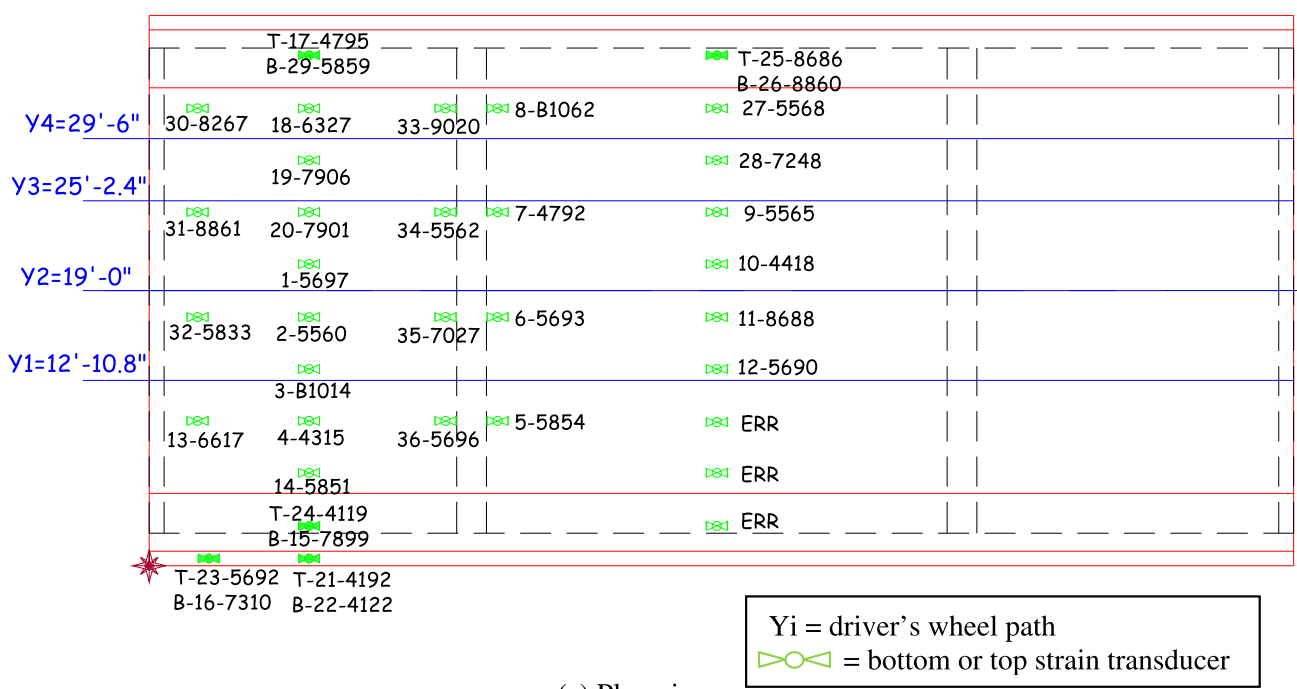

(a) Plan view

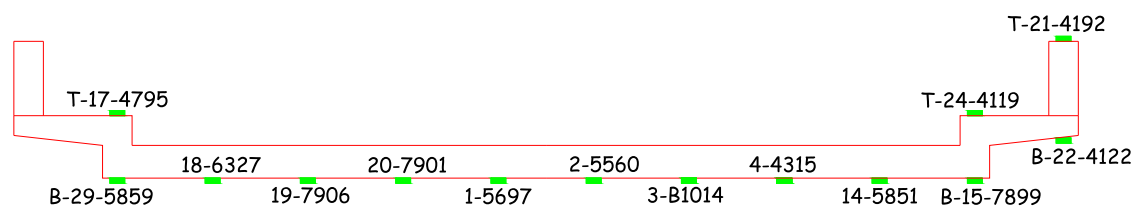

(b) Cross section

Fig. 3. Instrumentation plan for FSBR 1608.

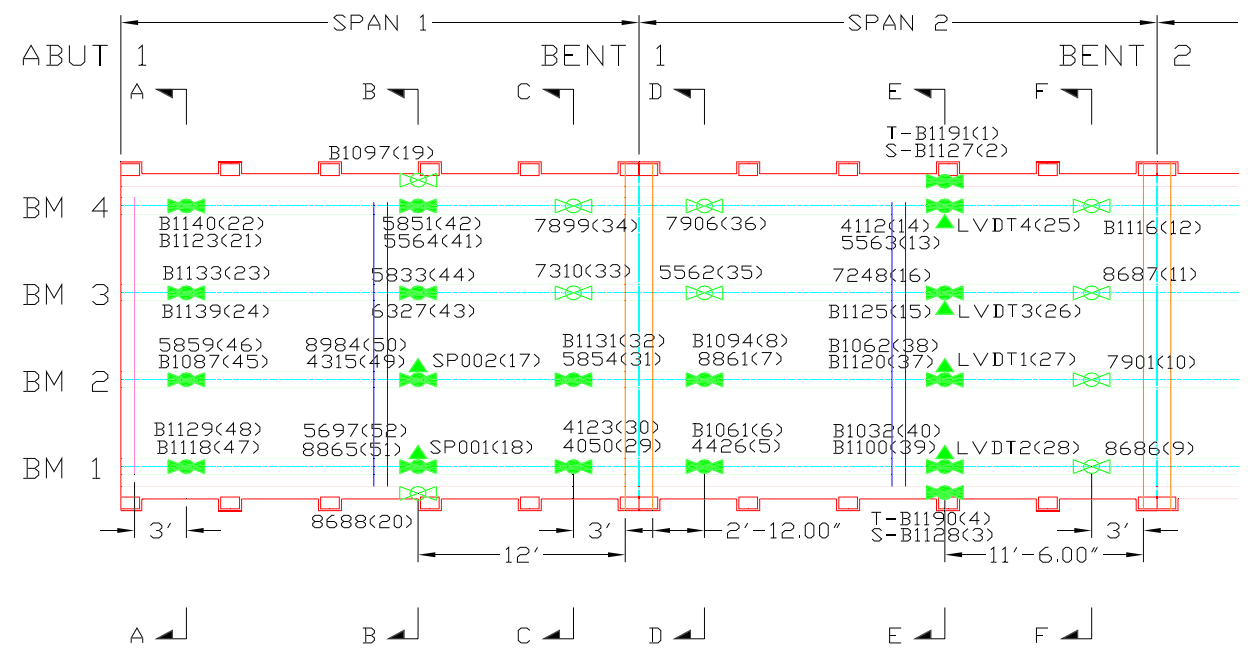

$\mathrm{Yi}=$ driver's wheel path

$\triangleright \bigcirc \triangleleft=$ top strain transducer

$-1=$ bottom strain transducer

(a) Plan view

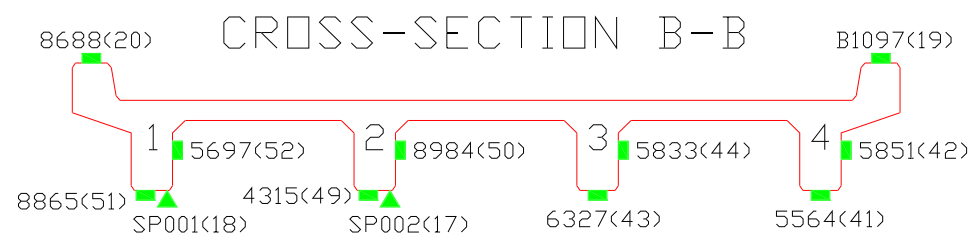

(b) Cross section

Fig. 4. Instrumentation plan for bridge 2151 
Table 2

Transducer extension length used for each bridge.

\begin{tabular}{|c|c|c|c|c|}
\hline Structure's name & Span length & Slab/beam depth & Number of transducers & Extension length \\
\hline FSBR 201 & $8.54 \mathrm{~m}(28 \mathrm{ft})$ & $82.55 \mathrm{~cm}$ (32.5 in.) & 28 & $30.48 \mathrm{~cm}$ (12 in.) \\
\hline FSBR 514 & $7.32 \mathrm{~m}(24 \mathrm{ft})$ & $39.37 \mathrm{~cm}$ (15.5 in.) & 24 & $30.48 \mathrm{~cm}$ (12 in.) \\
\hline FSBR 1608 & $10.06 \mathrm{~m}(33 \mathrm{ft})$ & $46.36 \mathrm{~cm}$ (18.25 in.) & 36 & $45.72 \mathrm{~cm}$ (18 in.) \\
\hline Bridge 2151 & $8.84 \mathrm{~m}(29 \mathrm{ft})$ & $73.66 \mathrm{~cm}$ (29.0 in.) & 46 & $38.10 \mathrm{~cm}$ (15 in.) \\
\hline
\end{tabular}

data, re-usable strain transducers were attached to the bottom of the slabs for bridges FSBR 514 and FSBR 16080 and at top and bottom of the beams for bridges FSBR 201 and 2151 as shown in Figs. 1-4. Since cracks were found on each superstructure, transducer extensions were used on all transducers to minimize the effects of cracks and thereby provide an averaged surface strain. The length of extension provided was a function of the slab/beam depths and span lengths as shown in Table 2. It was desirable to have a long enough gage length to provide an average surface strain that is representative of the flexural curvature, but a short enough gage length that so as to not be significantly effected by the moment gradients. The strain histories caused by the loading vehicle were recorded by the data acquisition system connected to the strain transducers. All transducers were attached to the con-

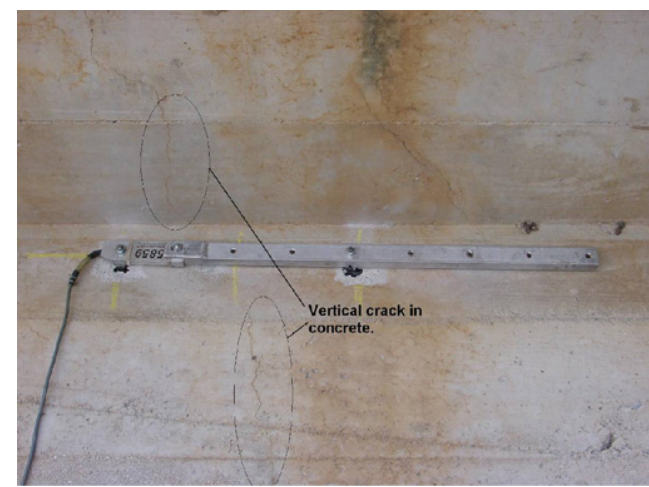

(a) FSBR 201

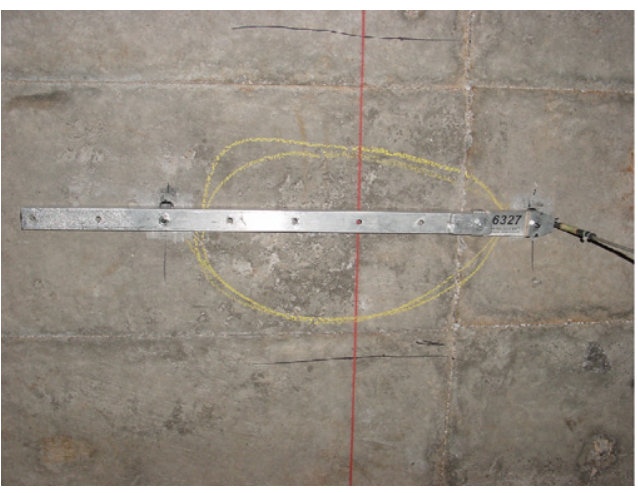

(c) FSBR 1608

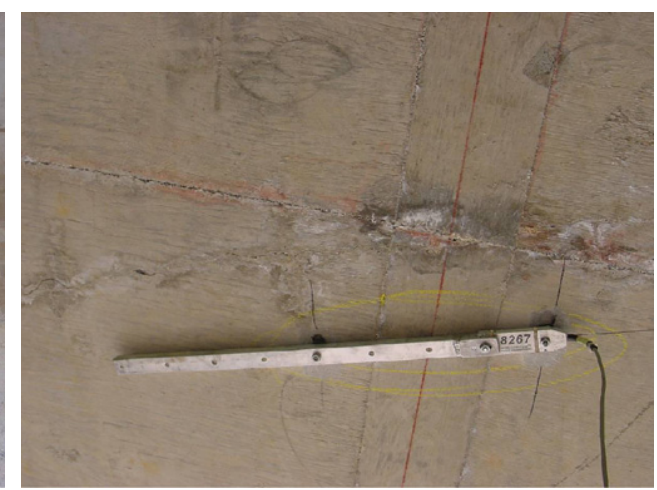

(b) FSBR 514

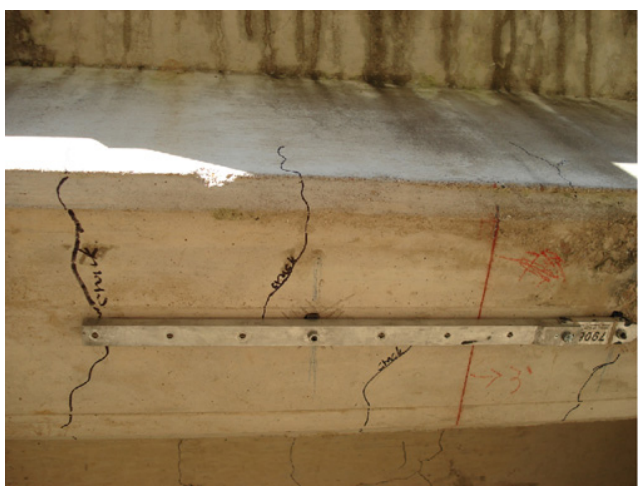

(d) Bridge 2151

Fig. 5. Attached transducers extension on each bridges.
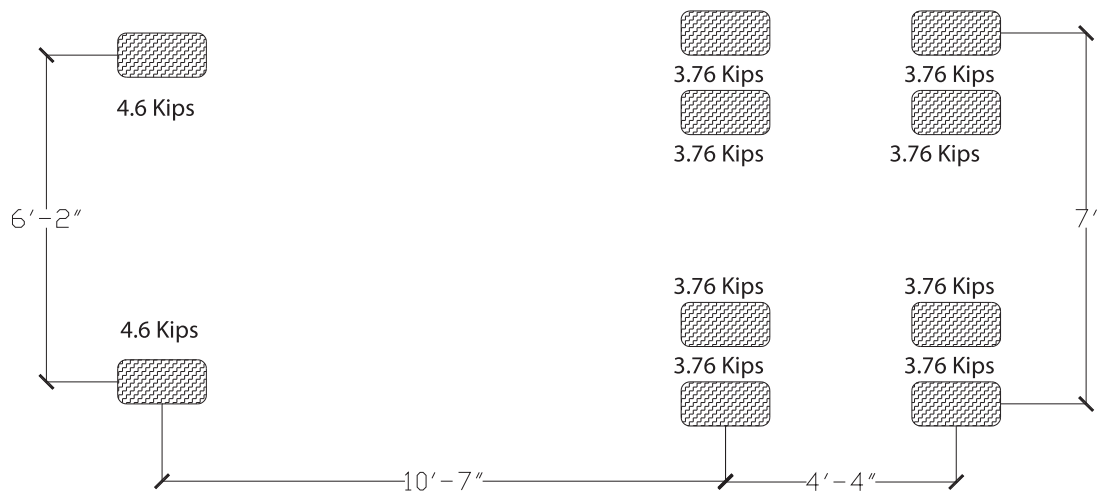

Fig. 6. Wheel configuration of the loading vehicle. 


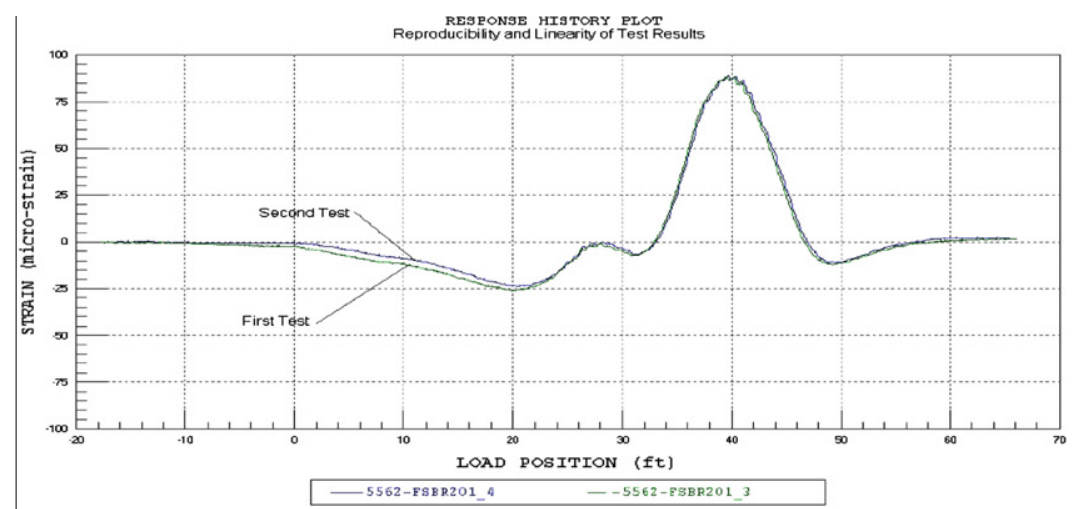

(a) FSBR 201

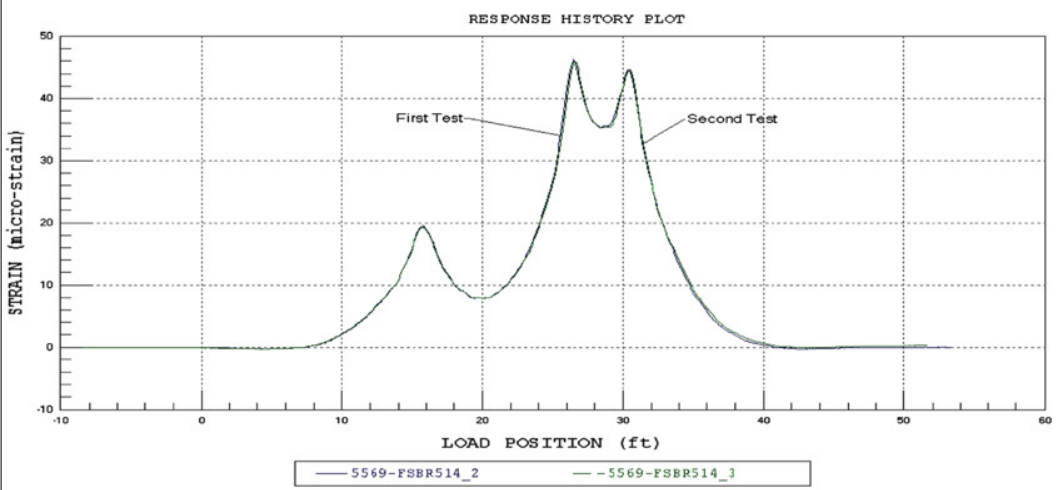

(b) FSBR 514

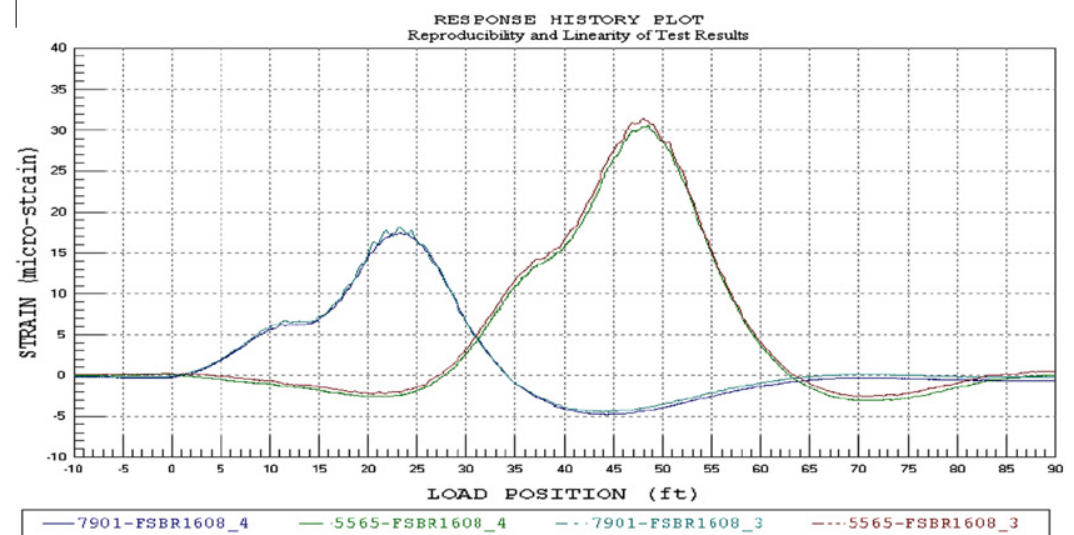

(c) FSBR 1608

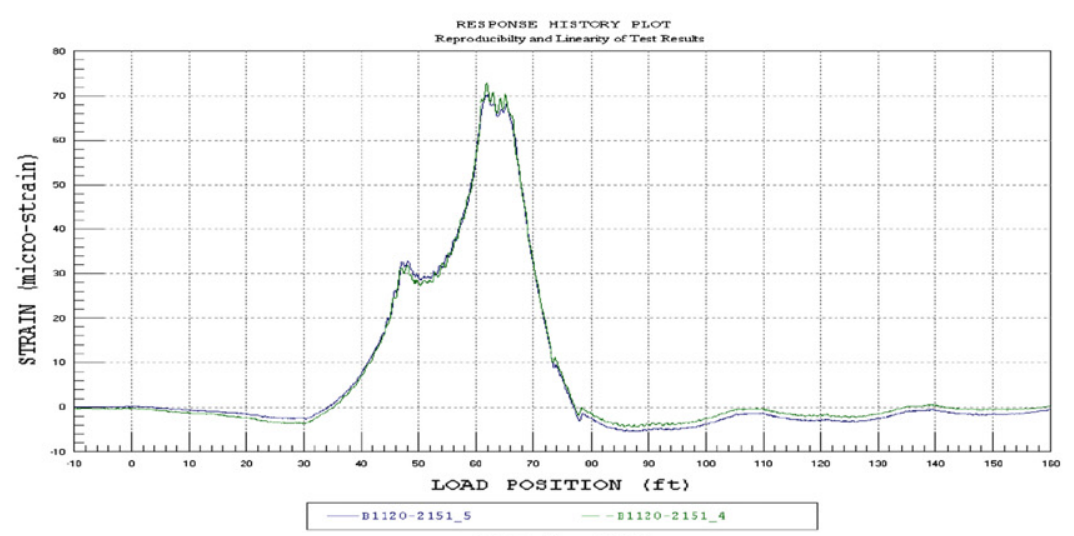

(d) Bridge 2151

Fig. 7. Reproducibility and linearity of test results. 
crete slab/beam surfaces using a quick-setting adhesive applied to special mounting tabs. Fig. 5 shows pictures of the attached strain transducers with extension on each of the bridges.

\subsection{Moving load and recorded data}

To perform the tests a single unit, three-axle dump truck with known axle weights was used to apply the load to the bridges. The wheel configuration of the loading vehicle is shown in Fig. 6. The total weight of the vehicle was chosen to be below 22.2 metric tons ( 20 short tons) to assure that the bridges do not exceed their linear-elastic ranges. The truck was driven across the entire length of the bridges at crawl speed, $8.05 \mathrm{kph}(5 \mathrm{mph})$, following prescribed paths as shown in Figs. 1-4. The longitudinal position of the truck was monitored remotely and recorded simultaneously with the strain measurements which were collected at a rate of $40 \mathrm{~Hz}$. To ensure good data records and to verify that the bridges response did not exceed the linear-elastic range, at least two separate runs were completed for each truck path. Fig. 7 shows typical strain history plots measured by the transducers for each of the bridges. In this figure we can also appreciate that the responses from identical truck paths were reproducible for each of the bridges. In addition, all strains measurements appeared to be linear with respect to load magnitude (truck position) and all strains returned to zero, indicating that the structure was acting in a linear elastic manner.

\subsection{GPR assessments}

GPR is a non-destructive testing method of evaluation that has been used in geological and archaeological investigations, road evaluations, utility investigations, and bridge inspections. When used for concrete evaluations it provides a fairly powerful tool used to identify subsurface concrete properties such as voids, cracks, and location of reinforcing steel. A GPR system consists of three main components (control unit, antenna, and survey wheel) and operates using electromagnetic waves which are propagated into the concrete surface and received by means of an antenna moving along the surface [9]. The antenna is a crucial component of the radar system since it determines the data quality, range resolution, and maximum depth of penetration.

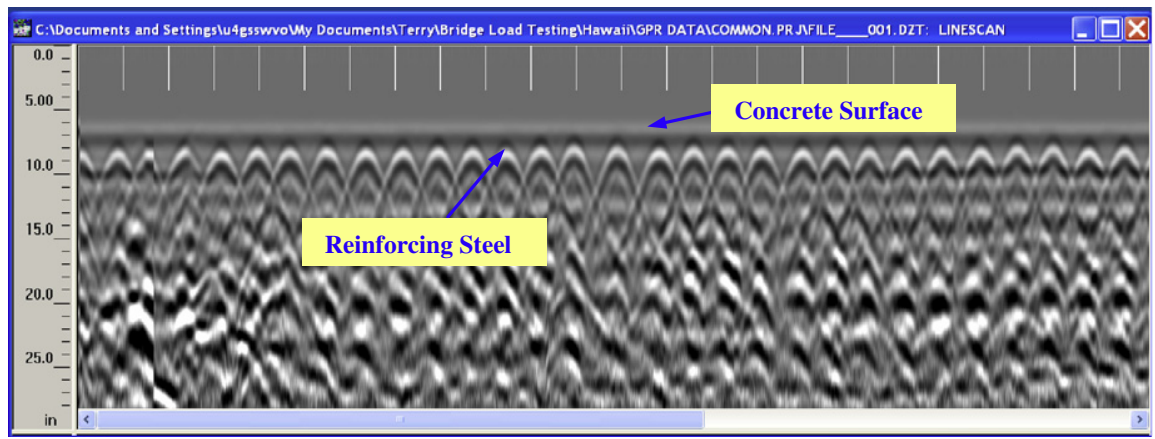

(a) Raw data

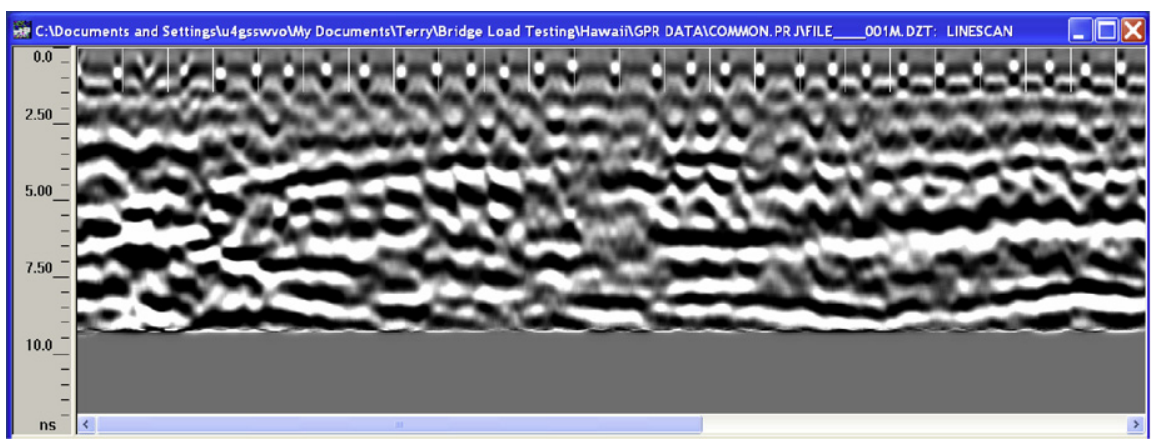

(b) Migrated data

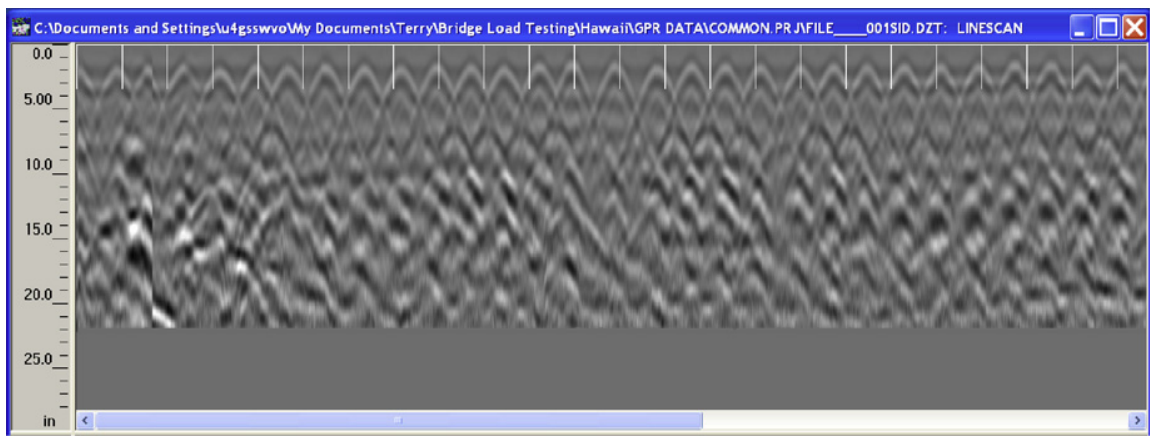

(c) Final results

Fig. 8. Migration processing procedure to achieve final results for FSBR 514. 
For these investigations since no plans were available for the tested structures, GPR was employed to determine location, depth and spacing of reinforcing steel within each of the reinforced concrete superstructures. The $1600 \mathrm{MHz}$ (GSSI Model 5100) antenna was used since it possesses a good combination of depth and resolution for the inspection of structural concrete. Once the reinforcing steel was located, small holes were drilled into the concrete to verify the size of the bars that were used. All holes were then filled with a two part concrete-epoxy to prevent any deterioration of the reinforcing steel. The structural members were then carefully mea- sured so that when combined with the GPR information, "as-built" plans could be developed. Note that no attempt was made to evaluate the piers, abutments or substructure during this study.

Fig. 8 shows the migration processing procedures used to achieve the final results for the evaluated bridges. This procedure reduces or eliminates hyperbolic diffraction patterns in the data. It basically takes out the tails of the hyperbolas to more accurately represent the location of the target. This process also offers a simple and accurate way of calculating the dielectric of the material your target is in from the shape of the hyperbolas (GSSI Handbook

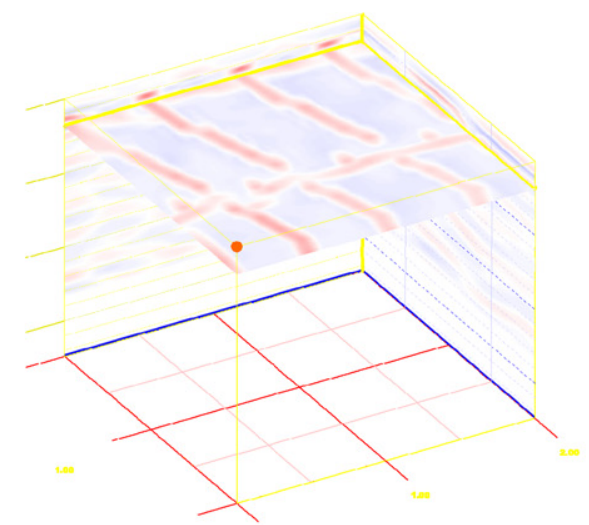

(a) FSBR 514 slab

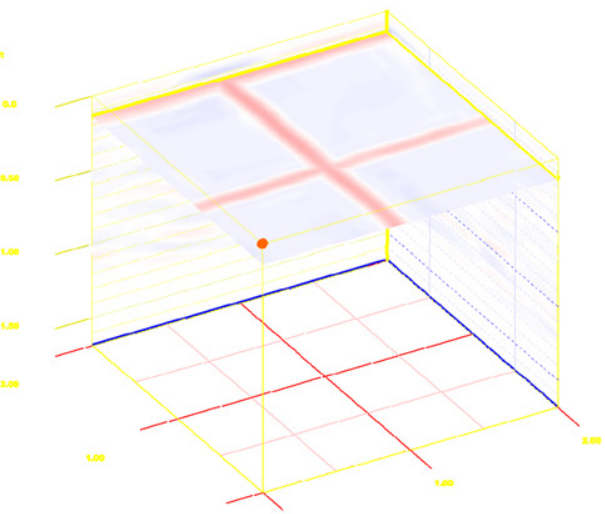

(b) FSBR 514 walls
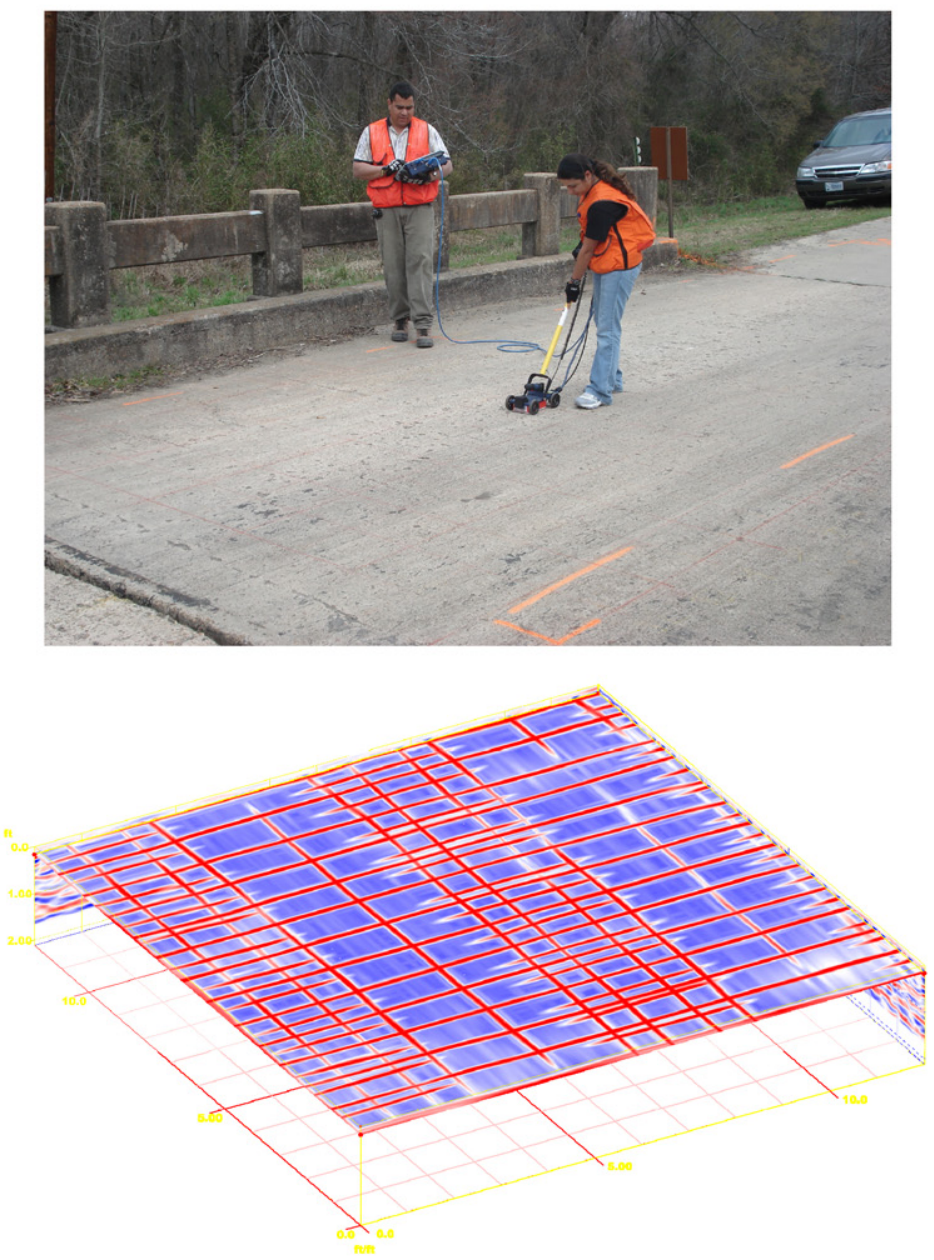

(c) Bridge 2151

Fig. 9. Three dimensional representation of internal reinforcement. 
for RADAR Inspection of Concrete). Note that in Fig. 8b each hyperbola has been collapsed into dots which mean that the dielectric of the material is appropriate. After the migration process has been completed, the final data shows the corresponding location and spacing of the reinforcing steel in the slab (Fig. 8c).

Additionally, if a 2D grid is created in the field, a 3D representation of the internal reinforcement can be created as shown in Fig. 9. The 3D representation offers another powerful tool to evaluate the data. For example, Fig. 9a shows that the main steel reinforcement in the slab for FSBR was skewed while the reinforcement in the walls was not (Fig. 9b). These results were expected due to the skew angle of the bridge. Fig. 9c shows the result from a $3.66 \mathrm{~m} \times 3.66 \mathrm{~m}(12 \mathrm{ft} \times 12 \mathrm{ft})$ grid performed in bridge 2151 . From this figure is easy to distinguish where two of the concrete beams were located with respect to the grid. Fig. 10 shows the internal reinforcement for each of the bridge's superstructures gathered from GPR evaluations. The internal reinforcement was then used to calculate the nominal capacities for each of the superstructures in order to obtain the safe load-carrying capacity for each of the load tested bridges.

\subsection{Modeling, analysis and data correlation}

After all the field data was examined to determine its quality, finite element models (FEM) were developed to provide a qualitative assessment of the structure's live-load response that would be representative of the bridges behavior. The main purpose was to correlate the FEM to the gathered field data to rate these bridges for civilian and military moving loads.

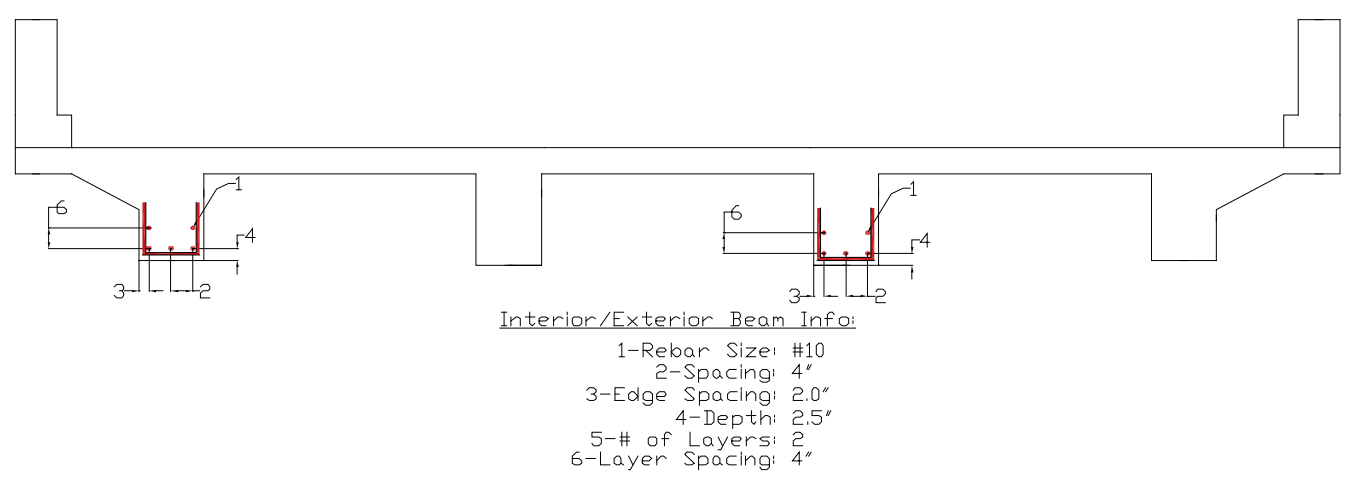

(a) FSBR 201

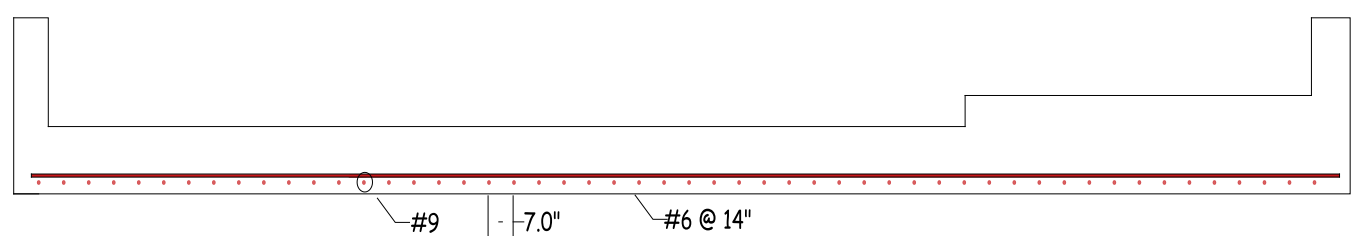

(b) FSBR 514

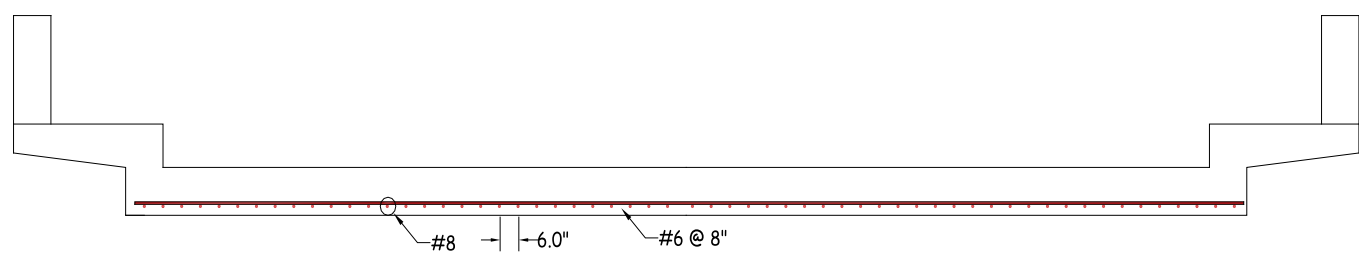

(c) FSBR 1608
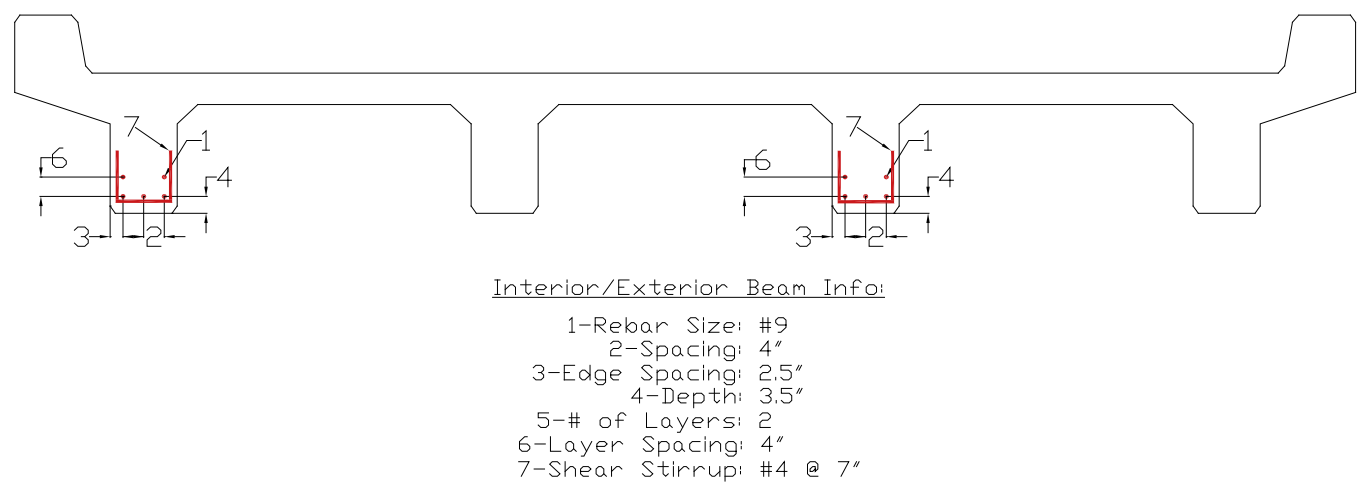

(d) Bridge 2151

Fig. 10. Cross section reinforcement details from GPR 
In order to build up an initial model, a planar grid primary composed of shell elements, beam elements, and springs was developed. Shell elements were used to model the slab or deck, beam elements were used to model the beams, diaphragms, and curbs, while spring elements were used to model the abutments and pier conditions for each of the bridges. Fig. 11 shows the planar grid fi-

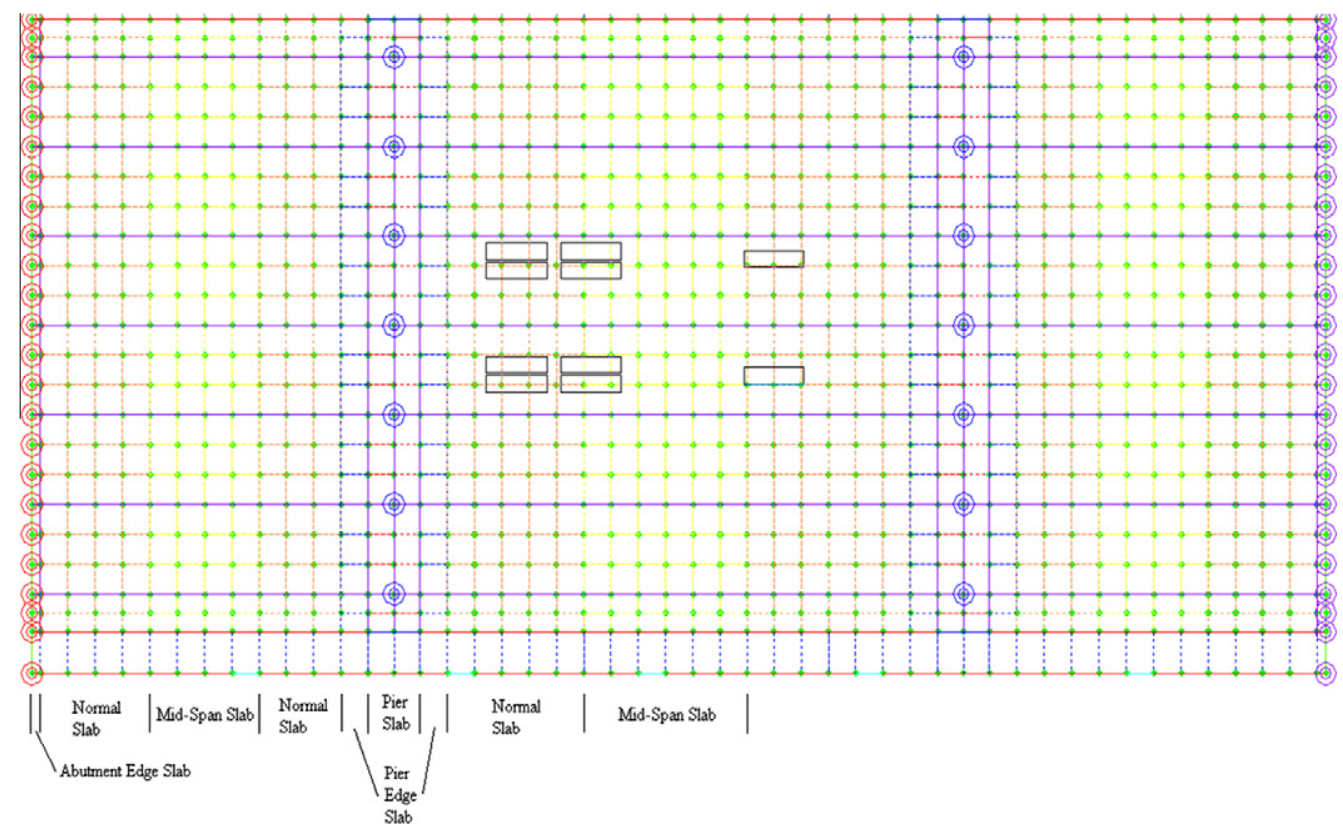

Fig. 11. Planar grid finite element model of FSBR 1608 superstructure.

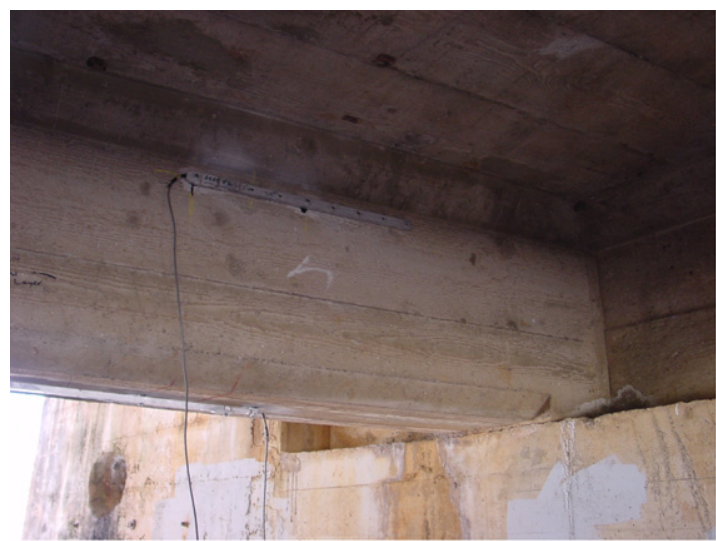

(a) FSBR 201

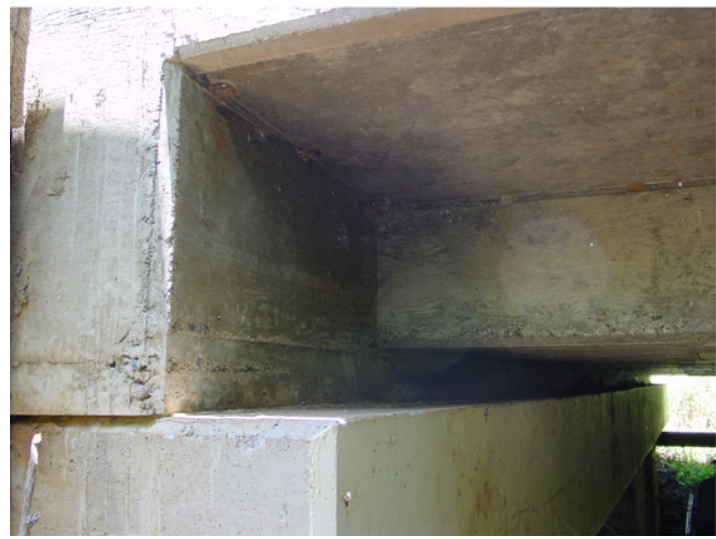

(c) FSBR 1608

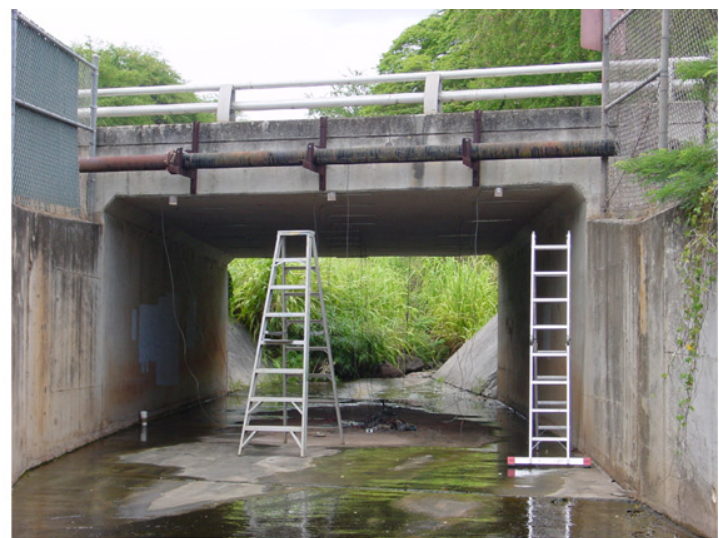

(b) FSBR 514

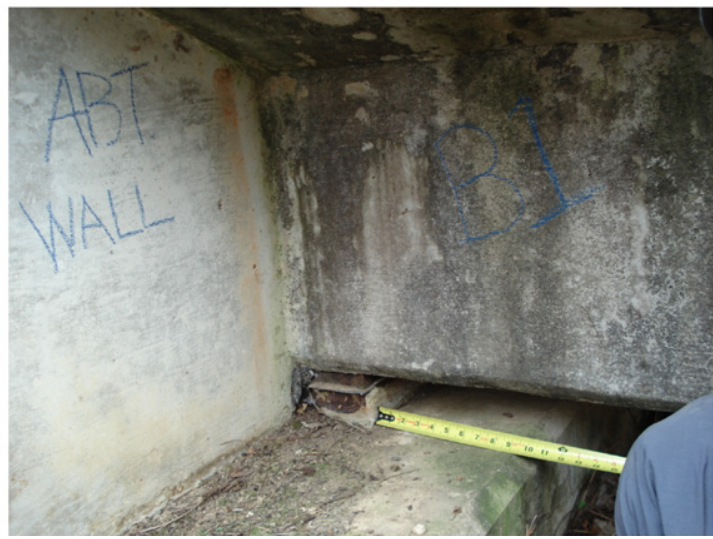

(d) Bridge 2151

Fig. 12. Support conditions at the abutments. 
RESPONSE HISTORY PLOT

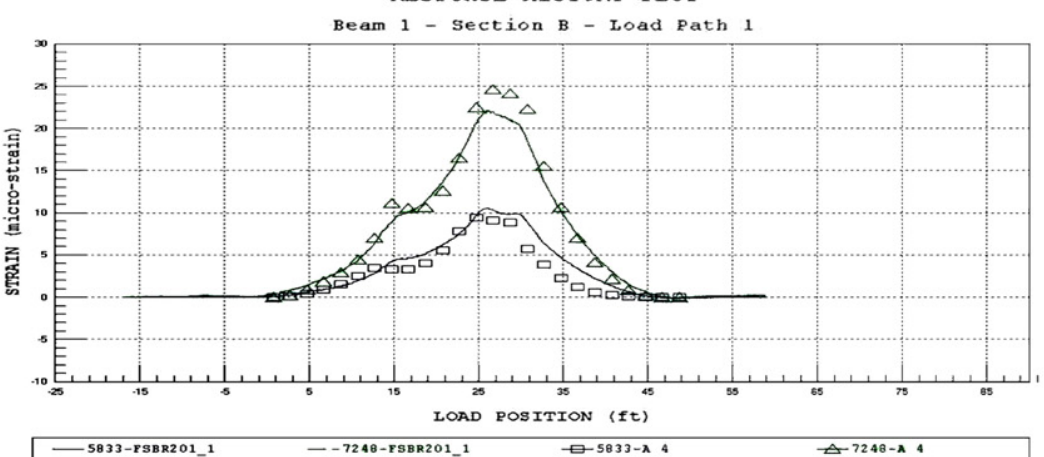

(a) FSBR 201

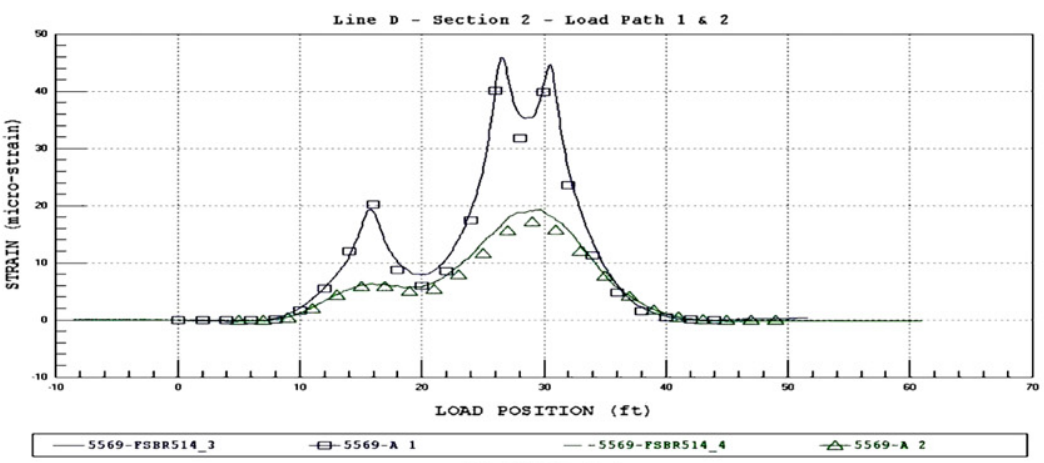

(b) FSBR 514

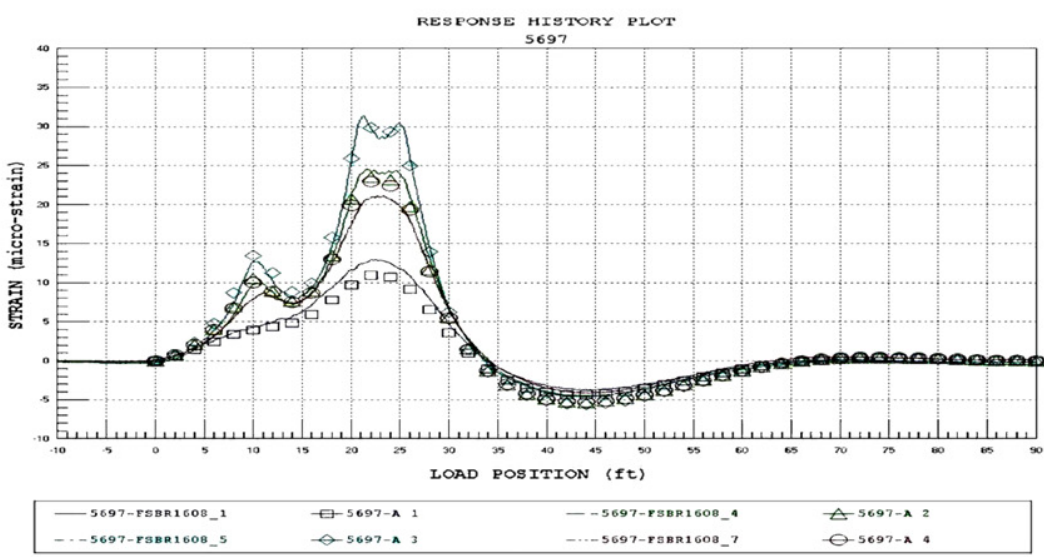

(c) FSBR 1608

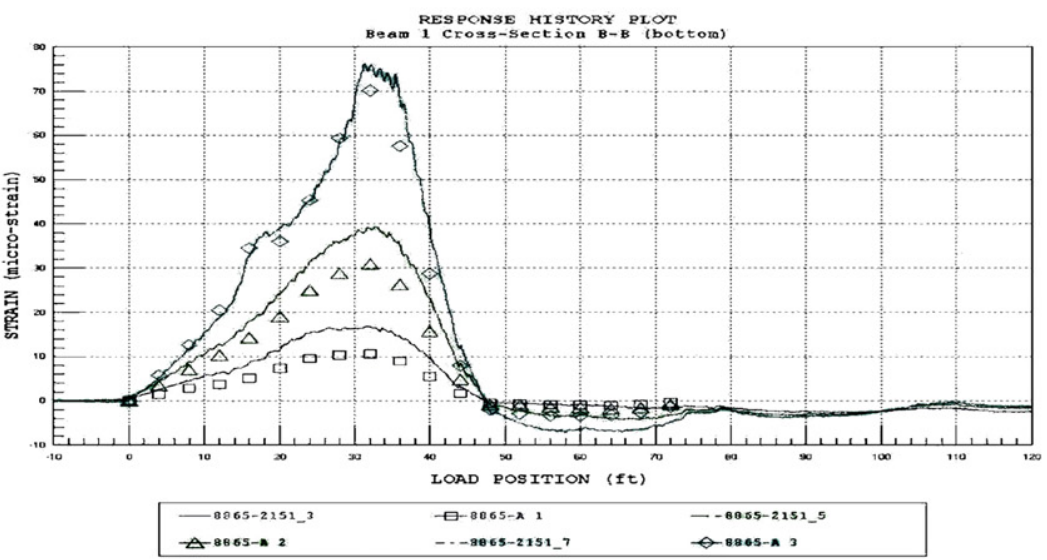

(d) Bridge 2151

Fig. 13. Measured vs. computed (modeled) strain comparison. 
Table 3

Model calibration results.

\begin{tabular}{lllll}
\hline Structure's name & FSBR & FSBR & FSBR & Bridge \\
& 201 & 514 & 1608 & 2151 \\
\hline $\begin{array}{l}\text { Number of load positions } \\
\text { Number of lateral load }\end{array}$ & 25 & 23 & 46 & 19 \\
$\quad 4$ & 2 & 4 & 3 \\
paths & & & & \\
Total load positions & 100 & 46 & 184 & 57 \\
Number of strain points & 26 & 19 & 34 & 42 \\
Total strain comparisons & 2600 & 874 & 6256 & 2394 \\
Percent error (\%) & 5.8 & 8.3 & 11.0 & 3.9 \\
Scale error (\%) & 17.8 & 7.5 & 4.7 & 4.2 \\
Correlation coefficient & 0.971 & 0.958 & 0.955 & 0.980
\end{tabular}

nite element model used for the FSBR 1608 superstructure. The type of analysis used to model each of the superstructures was the linear-elastic finite element-stiffness method.

Once the models were developed, the load testing procedures for each of the tested bridges were essentially reproduced into the models. A two-dimensional "footprint" of the loading vehicle was applied to the model along the same paths that the actual test vehicle crossed the bridge. A direct comparison of strain values was then made between the modeled predictions and the experimentally-measured results. The initial model was then "calibrated" by modifying various properties and boundary conditions until the results matched those measured in the field. In general, the parameters modified to calibrate the initial model consisted in the adjustment of rotational and axial springs at supports and the modulus of elasticity of the deck/slab, beams, parapet, diaphragms, sidewalks, etc. Usually, when a load test is performed, restraint effects at the support are considered unreliable because they can be the result of a friction resistance force that may not be dependable when heavier loads are applied to the structure. However, for each of these bridges they were considered partially reliable because of the type of support at the abutments. For all of the bridges, the abutment supports were not a typical bearing, in fact, all of the superstructures (concrete beams or slabs) were embedded in the concrete abutment as shown in Fig. 12. Finally, by modifying the different parameters a calibrated model was obtained for each of the bridges. Fig. 13 provides a visual examination of the response histories between the measured and computed (modeled) strains. Table 3 summarizes the model calibration results for each of the bridges.

\section{Load rating procedures and results}

Once the finite element model was calibrated to field conditions for each of the bridges, engineering judgment was used to address any optimized parameters that may change over time or that may be unreliable with heavy loads or future damage. For example, for FSBR 201 the stiffness of the parapet and the end-restraint provided by the beam bearings were removed. This was due to the assumption that when the bridge was constructed, the parapet was poured separate from the deck and T-beams; therefore it could not contribute to the dead-load resistance. End-restraints are likely time dependent with respect to load duration and load rate. It was therefore conservatively assumed that the end-restraints were not providing significant resistance to the dead-load.

For structure FSBR 514 none of the optimized parameters were considered to be unreliable, however the amount of steel reinforcement for negative moment at the abutments was not defined so the moment capacity of the slab ends could not be obtained. Therefore, to insure a conservative rating, it was assumed that the slab would fail in negative moment at the abutments prior to failing at mid-span. This condition was simulated by removing the endrestraints provided by the spring elements. The resulting load capacity was then controlled by the mid-span moment after a hinge condition was induced at the abutments.

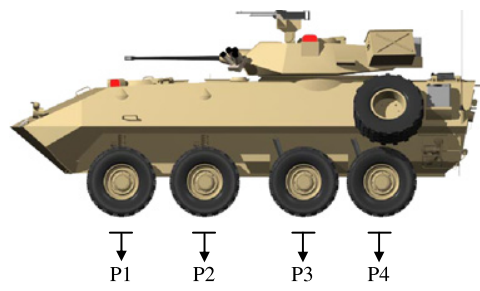

(a) Side View (Picture from: www.turbosquid.com)

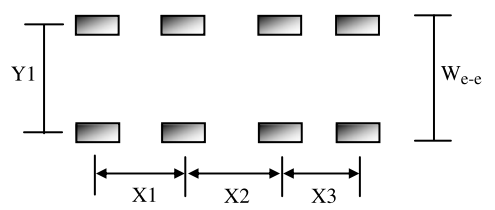

(b) Top View

\begin{tabular}{|c|c|c|c|c|}
\hline \multicolumn{5}{|c|}{ Loading Data } \\
\hline \multirow{2}{*}{ Axle Weights (k) } & P1 & P2 & P3 & P4 \\
\hline & 9.8 & 9.8 & 10.9 & 10.7 \\
\hline \multicolumn{5}{|c|}{ Dimensions } \\
\hline \multirow{2}{*}{ Transverse Spacing (ft) } & $W_{\text {e-e }}$ & Y1 & & \\
\hline & 8.97 & 7.25 & & \\
\hline Longitudinal Spacing (ft) & $\mathrm{X} 1$ & $\mathrm{X} 2$ & X3 & \\
\hline
\end{tabular}

Fig. 14. Configuration of LAVIII-STRYKER vehicle load distribution. 


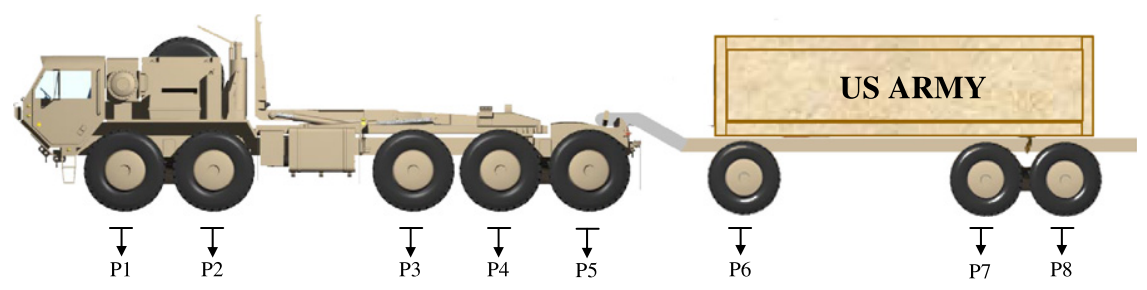

(a) Side View (Picture edited from: www.turbosquid.com)

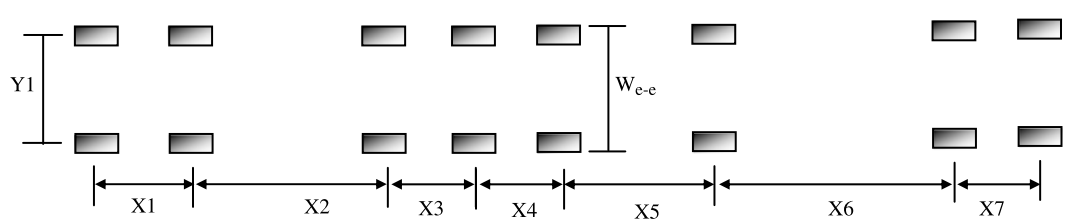

(b) Top View

\begin{tabular}{||c|c|c|c|c|c|c|c|c||}
\hline \multicolumn{9}{||c||}{ Loading Data } \\
\hline \multirow{2}{*}{ Axle Loads (k) } & $\mathrm{P} 1$ & $\mathrm{P} 2$ & $\mathrm{P} 3$ & $\mathrm{P} 4$ & $\mathrm{P} 5$ & $\mathrm{P} 6$ & $\mathrm{P} 7$ & $\mathrm{P} 8$ \\
\cline { 2 - 11 } & 11.4 & 11.4 & 21.2 & 21.2 & 21.2 & 9.8 & 20.6 & 20.6 \\
\hline \multicolumn{7}{|c||}{ Dimensions } \\
\hline $\begin{array}{c}\text { Transverse Spacing } \\
(\mathrm{ft})\end{array}$ & $\mathrm{W}_{\mathrm{e}-\mathrm{e}}$ & $\mathrm{Y} 1$ & & & & & & \\
\cline { 2 - 11 } & 8.0 & 6.67 & & & & & & \\
\hline $\begin{array}{c}\text { Longitudinal Spacing } \\
(\mathrm{ft})\end{array}$ & $\mathrm{X} 1$ & $\mathrm{X} 2$ & $\mathrm{X} 3$ & $\mathrm{X} 4$ & $\mathrm{X} 5$ & $\mathrm{X} 6$ & $\mathrm{X} 7$ & \\
\cline { 2 - 12 } & 5.0 & 11.2 & 5.0 & 5.0 & 8.5 & 10.0 & 4.6 & \\
\hline \hline
\end{tabular}

Fig. 15. Configuration of PLS vehicle load distribution.

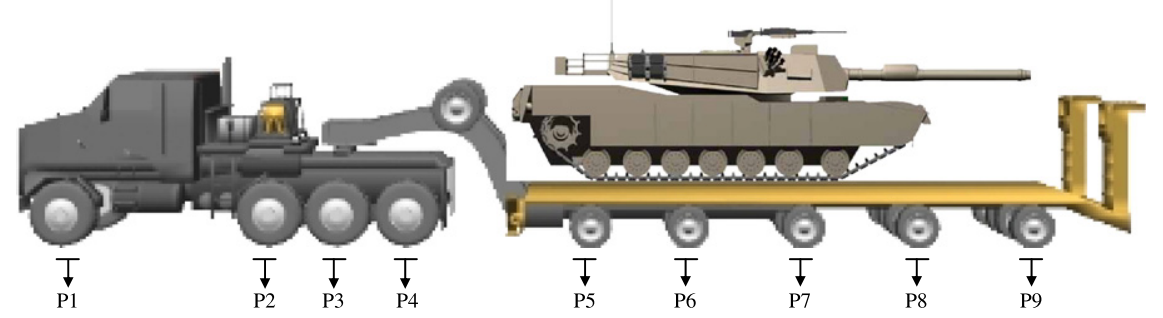

(a) Side View (Picture edited from: www.turbosquid.com)

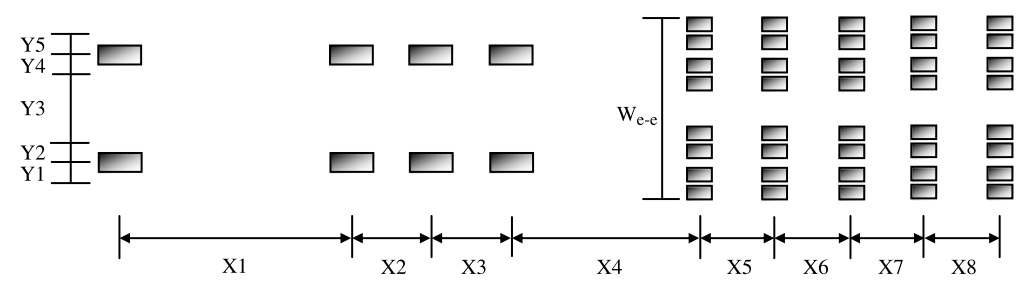

(b) Top View

\begin{tabular}{||c|c|c|c|c|c|c|c|c|c||}
\hline \multicolumn{10}{|c||}{ Loading Data } \\
\hline \multirow{2}{*}{ Axle Loads (k) } & P1 & P2 & P3 & P4 & P5 & P6 & P7 & P8 & P9 \\
\cline { 2 - 12 } & 21.7 & 22.3 & 21.7 & 19.9 & 27.0 & 29.7 & 28.0 & 28.0 & 31.4 \\
\hline \multicolumn{10}{|c||}{ Dimensions } \\
\hline $\begin{array}{c}\text { Transverse Spacing } \\
\text { (ft) }\end{array}$ & $\mathrm{W}_{\text {e-e }}$ & $\mathrm{Y} 1$ & $\mathrm{Y} 2$ & $\mathrm{Y} 3$ & $\mathrm{Y} 4$ & $\mathrm{Y} 5$ & & & \\
\cline { 2 - 14 } & 12.0 & 1.67 & 1.12 & 4.85 & 1.12 & 1.67 & & & \\
\hline $\begin{array}{c}\text { Longitudinal } \\
\text { Spacing (ft) }\end{array}$ & $\mathrm{X} 1$ & $\mathrm{X} 2$ & $\mathrm{X} 3$ & $\mathrm{X} 4$ & $\mathrm{X} 5$ & $\mathrm{X} 6$ & $\mathrm{X} 7$ & $\mathrm{X} 8$ & \\
\cline { 2 - 14 } & 12.92 & 5.0 & 5.0 & 15.94 & 5.94 & 5.94 & 5.94 & 5.94 & \\
\hline \hline
\end{tabular}

Fig. 16. Configuration of HETS vehicle load distribution. 
Table 4

Moment and shear rating factors for FSBR 201

\begin{tabular}{|c|c|c|c|c|c|}
\hline \multirow[t]{2}{*}{ Truck } & \multirow[t]{2}{*}{ Location } & \multicolumn{2}{|c|}{ Inventory RF } & \multicolumn{2}{|c|}{ Operating RF } \\
\hline & & Moment & Shear & Moment & Shear \\
\hline \multirow[t]{2}{*}{ HS-20 } & Exterior beam & 3.32 & 1.83 & 4.30 & 2.37 \\
\hline & Interior beam & 1.43 & 1.84 & 1.85 & 2.39 \\
\hline \multirow[t]{2}{*}{ Type 3} & Exterior beam & 4.08 & 2.33 & 5.29 & 3.02 \\
\hline & Interior beam & 1.64 & 2.30 & 2.13 & 2.98 \\
\hline \multirow[t]{2}{*}{ Type 3-3 } & Exterior beam & 4.98 & 2.82 & 6.46 & 3.66 \\
\hline & Interior beam & 1.99 & 2.81 & 2.58 & 3.64 \\
\hline \multirow[t]{2}{*}{ Type 3S2 } & Exterior beam & 4.39 & 2.50 & 5.69 & 3.24 \\
\hline & Interior beam & 1.74 & 2.46 & 2.26 & 3.19 \\
\hline \multirow[t]{2}{*}{ LAVIII-Stryker } & Exterior beam & 5.06 & 2.70 & 6.56 & 3.50 \\
\hline & Interior beam & 1.93 & 2.69 & 2.50 & 3.49 \\
\hline \multirow[t]{2}{*}{ PLS } & Exterior beam & 2.81 & 1.57 & 3.64 & 2.04 \\
\hline & Interior beam & 1.29 & 1.81 & 1.67 & 2.35 \\
\hline \multirow[t]{2}{*}{ HETS } & Exterior beam & 3.30 & 1.74 & 4.28 & 2.26 \\
\hline & Interior beam & 1.04 & 1.47 & 1.35 & 1.91 \\
\hline
\end{tabular}

Table 5

Moment rating factors for FSBR 514

\begin{tabular}{llll}
\hline Truck & Location & $\begin{array}{l}\text { Inventory RF } \\
\text { Mid-span }\end{array}$ & $\begin{array}{l}\text { Operating RF } \\
\text { Mid-span }\end{array}$ \\
\hline HS-20 & Deck & 2.19 & 2.84 \\
Type 3 & Deck & 2.88 & 3.73 \\
Type 3S2 & Deck & 3.17 & 4.11 \\
Type 3-3 & Deck & 3.52 & 4.56 \\
LAVIII-Stryker & Deck & 2.11 & 2.74 \\
PLS & Deck & 2.70 & 3.50 \\
HETS & Deck & 2.49 & 3.23 \\
\hline
\end{tabular}

Table 6

Moment rating factors for FSBR 1608.

\begin{tabular}{llll}
\hline Truck & Location & $\begin{array}{l}\text { Inventory RF } \\
\text { Mid-span }\end{array}$ & $\begin{array}{l}\text { Operating RF } \\
\text { Mid-span }\end{array}$ \\
\hline HS-20 & Deck & 1.30 & 1.69 \\
Type 3 & Deck & 1.65 & 2.14 \\
Type 3S2 & Deck & 1.83 & 2.37 \\
Type 3-3 & Deck & 2.06 & 2.67 \\
LAVIII-Stryker & Deck & 1.92 & 2.49 \\
PLS & Deck & 1.62 & 2.10 \\
HETS & Deck & 1.34 & 1.74
\end{tabular}

In the case of structure FSBR 1608, almost all optimized parameters remained the same for rating purposes. One change that was made to add a level of conservatism to the ratings was that the modulus of elasticity of the deck elements located next to the pier elements were reduced by approximately $50 \%$. This was done to account for the possibility that the negative moment regions would reach ultimate moment capacities before the mid-span regions reached ultimate moment. Again this was assumed because the only steel reinforcement information available was the size, depth and spacing of the mid-span section. Therefore, this structure could only be rated for positive moment at mid-span.

For bridge 2151, the stiffness of the springs at the abutments was conservatively reduced by $50 \%$ to account for the possibility that the restraint may be slightly dependant on the weather or other unknown factors. The pier springs were reduced to zero since it is likely that the friction is time dependant with respect to load duration and load rates. Reducing end-restraint values is a conservative approach which results in an increase in live-load mid-span moment and a lower load rating.

Finally, the safe load-carrying capacity following the "AASHTO Manual for Condition Evaluation and Load and Resistance Factor Rating (LRFR) of Highway Bridges October 2003 Edition" [2] was calculated for each of the superstructures. Load rating factors were

Table 7

Moment and shear rating factors for bridge 2151 .

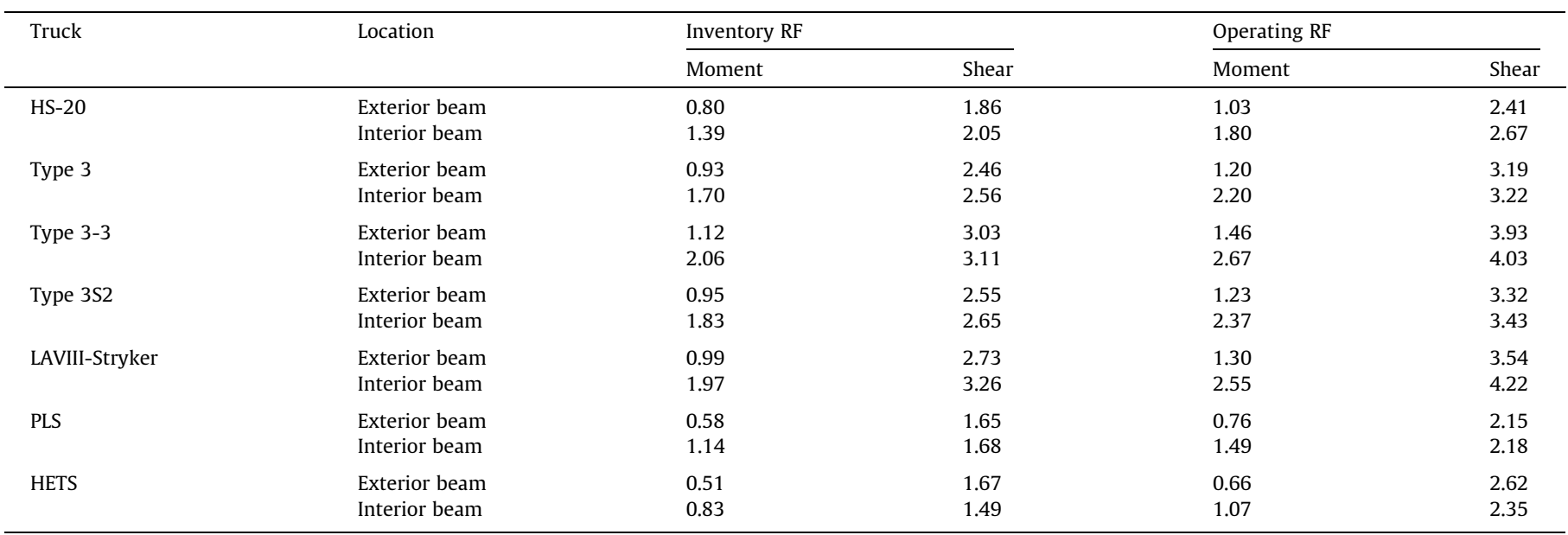


calculated for the standard AASHTO vehicles and selected military vehicles. Section capacities were calculated based on the results from the steel investigation and some basic assumptions. Since the steel investigation could only determine the size and location of the reinforcing steel, the steel strength had to be assumed. The age of the structures was not known, but it was assumed to have been built prior to 1954 . Therefore, a yield stress $\left(f_{\mathrm{y}}\right)$ of $33 \mathrm{ksi}$ was assumed for the reinforcing steel of each structure [1]. Additionally, the concrete strength $\left(f_{\mathrm{c}}\right)$ was conservatively assumed to be $3 \mathrm{ksi}$. All the factors designated by the LRFR were considered in the load rating with the exception of the distribution factor. The distribution factors were obtained from the calibrated models, specifically for the military vehicles, since the load configuration for these vehicles varies considerably from the standard $1.83 \mathrm{~m}$ $(6 \mathrm{ft})$ wheel gauge. Therefore, distribution factors established by AASHTO cannot be used to accurately estimate the live load distribution factor for these vehicles. Figs. 14-16 show the load configuration for the selected military vehicles. Tables 4-7 contain the controlling LRFR rating factors for each of the selected vehicles for inventory and operating levels.

\section{Conclusions and recommendations}

Results from these tests show that a diagnostic load test combine with GPR evaluations can be a valuable tool to obtain the safe load-carrying capacity of bridges. Diagnostics load test provide the necessary tools to calibrate a finite element model that in fact will be representative of the bridges' behavior. These models can be used to obtain load ratings for civilian and military vehicles that otherwise will be very difficult to obtain to perform a proof load test. However, engineering judgment is required to remove undesirable effects to yield an acceptable safe load-carrying capacity of the structure.

This article presented the results obtained for four reinforced concrete bridges on US Army installations. All load tested bridges rated satisfactory for the inventory level for bending moment and shear force with the exception of bridge 2151. However, this structure rated satisfactory for civilian vehicles in the operating level. Therefore, is up to the owner to decide the level of operation that they may want to post. The load rating for two of the three military vehicles was below the satisfactory condition even for the operating level. Therefore, the following recommendations are presented.

Since the roadway width is less than $6.10 \mathrm{~m}$ (20 ft), it would be difficult for two military vehicles to cross the bridge at the same time. Additionally, the volume of traffic on this bridge is exceptionally low. Therefore, it can be required that only one military vehicle can be on the bridge at a time. Also, it can be required to cross these vehicles at a crawl speed (less than $8 \mathrm{kph}$ ) to allow an impact factor reduction to zero. Is also recommended to restrict military vehicles traffic to the center of the roadway since the interior girders rated reasonably well compared to the exterior girders.

\section{Acknowledgement}

The tests described and the resulting data presented herein, unless otherwise noted, were obtained from research conducted under the US Army Transportation Infrastructure Program for the Installation Management Command (IMCOM). Permission to publish was granted by Director, Geotechnical and Structures Laboratory of US Army Corps of Engineers - Engineering Research and Development Center.

\section{References}

[1] American Association of State Highway and Transportation Officials (AASHTO). AASHTO LRFD bridge design specifications, 3rd ed. Washington, DC; 2004.

[2] American Association of State Highway and Transportation Officials (AASHTO). Manual for the Condition Evaluation and Load and Resistance Factor Rating (LRFR) of highway bridges, Washington, DC; 2003.

[3] Barker MG. Quantifying field-test behavior for rating steel girder bridges. J Bridge Eng, ASCE 2001;6(4):254-61.

[4] Cai CS, Shahawy M. Understanding capacity rating of bridges from load tests. Pract Period Struct Des Constr, ASCE 2005;8(4):209-16.

[9] Maierhofer C. Nondestructive evaluation of concrete infrastructure with ground penetrating radar. J Mater Civil Eng, ASCE 2003;15(3):287-97.

\section{Further reading}

[5] Chajes MJ, Shenton HW. Using diagnostic load tests for accurate load rating of typical bridges. Bridge Struct 2006;2(1):13-23.

[6] Chajes MJ, Mertz DR, Commander B. Experimental load rating of a posted bridge. J Bridge Eng, ASCE 1997;2(1):1-10.

[7] Fu CC et al. Lateral distribution factor from bridge field testing. J Struct Eng, ASCE 1996;122(9):1106-9.

[8] Lichtenstein AG. Manual for bridge rating through load testing. Research results digest, No. 234, National Cooperative Highway Research Program, Washington, DC; 1998. 